INTERVENTIONAL CARDIOLOGY AND SURGERY

\title{
Shortening the stent length reduces restenosis with bare metal stents: matched pair comparison of short stenting and conventional stenting
}

\author{
U Dietz, N Holz, C Dauer, H Lambertz
}

See end of article for authors' affiliations

Correspondence to: Dr Ulrich Dietz, Deutsche Klinik für Diagnostik, Aukammallee 33, D65191 Wiesbaden, Germany; dietz.kardio@ $\mathrm{dkd}$-wiesbaden.de

Accepted 11 February 2005

Published Online First 9 May 2005
Objective: To investigate the effect of reducing stent length on the rate of target lesion restenosis. Design: In a prospective investigation, acute and long term results of a short stenting procedure were analysed by quantitative angiography and compared with results of a conventional stenting procedure selected according to a matched pairs analysis.

Patients: Short stents were implanted in 400 consecutive patients with 464 lesions and conventional stents in 430 patients. Demographic and lesion characteristics were comparable between groups.

Interventions: In short stenting, the shortest stent length to cover only segments with $>30 \%$ reduction in vessel diameter was used. In conventional stenting, full coverage of a stenotic vessel segment was intended.

Main outcome measures: The mean stent lengths of the short stent group $(9.8(4) \mathrm{mm})$ and the conventional stent group (16.3 (7) $\mathrm{mm}$ ) differed significantly $(p<0.0001)$; all other procedural and angiographic parameters were the same. Procedural success was similar for both groups. Control angiography after six months was conducted in $92 \%$ of patients.

Results: Short stenting resulted in both less restenosis (68 of 431 (15.8\%)) than conventional stenting (93 of $381(24.4 \%), p=0.007)$ and less late lumen loss $(0.6(0.6) \mathrm{mm} v 0.75(0.5) \mathrm{mm}, \mathrm{p}=0.0001)$. Residual stenosis $(<45 \%)$ in adjacent vessel segments after short stenting did not affect the restenosis rate. Only the implantation of $a \leqslant 9 \mathrm{~mm}$ stent predicted the absence of restenosis in a multivariate analysis.

Conclusion: Shortening the length of bare metal stents reduces the restenosis rate as compared with conventional stenting.
$\mathrm{D}$ rug eluting stents (DES) have reduced restenosis rates compared with bare metal stents. ${ }^{1}$ However, the superiority of DES has been proved for only a few lesion characteristics. Another restriction for the liberal use of DES is their costs. A recently published cost effectiveness analysis for the use of DES showed that treatment with DES would save costs for patients with a bare metal stent target vessel revascularisation (TVR) rate $>20 \%{ }^{2}$ Although the length of the DES does not seem to influence the restenosis rate, the length of bare metal stents was found to predict restenosis independently. ${ }^{3}$ Furthermore, much longer stents were used than necessary to cover the target lesion in most lesions as reported in an analysis of several interventional trials of bare metal stents. ${ }^{5}$ In a previous study, we could show that, with a single short stent $(9 \mathrm{~mm}), 52 \%$ of all treated coronary lesions could be treated successfully, yielding a low restenosis rate. ${ }^{6}$ In the present study we compared the strategy of implanting the shortest stent length, covering only the clinically relevant parts of a lesion, with conventional stenting - that is, a stent sized to cover the target lesion completely.

\section{METHODS}

Objectives

The study was designed to investigate, prospectively, both the short term and long term results of inserting the shortest possible stent into lesions requiring a stent. Immediately adjacent plaques causing less than $30 \%$ diameter stenosis were left unstented. Possible effects of this procedure on the restenosis rate were assessed angiographically.

\section{Patients}

Four hundred consecutive patients attending our clinic between 2002 and 2003 with symptoms of angina pectoris or proven ischaemia and $>60 \%$ diameter stenosis requiring a stent were treated according to the protocol below. Also, a comparable number of matched control patients treated routinely between 1999 and 2001 by conventional stenting that completely covered the target lesions were selected from a registry. Lesions in the two groups of patients were pair matched on the basis of demographic (age, sex, and diabetes) and angiographic data (reference diameter, lesion length, and American Heart Association criteria for lesion morphology). Patients with acute myocardial infarction and target lesions $>30 \mathrm{~mm}$ long were excluded.

\section{Intervention}

Short stenting

Primary stenting was considered only for target lesions $<10 \mathrm{~mm}$ long located in a proximal segment of the left anterior descending coronary artery or the right coronary artery with a reference diameter $>3 \mathrm{~mm}$. In all of the remaining interventions percutaneous transluminal coronary angioplasty (PTCA) was the primary intervention. A stent was inserted if angiography performed five minutes after the initial intervention showed a residual stenosis $>30 \%$ according to visual assessment or a dissection that required a stent. In all cases we used the shortest possible stent

Abbreviations: DES, drug eluting stents; $M A C E$, major adverse cardiac events; PTCA, percutaneous transluminal coronary angioplasty; TVR, target vessel revascularisation 
compatible with immediate success according to visual assessment or online quantitative coronary angiographythat is, covering the most severe residual stenosis with a final diameter stenosis $<30 \%$ within the stent and $<50 \%$ diameter stenosis of the target vessel without need of an additional stent. The intended inflation pressure was $>12 \mathrm{~atm}$ for all stent implantations. The nominal stent size was chosen to achieve a final stent to artery ratio of 1.1 at the inflation pressure used.

\section{Conventional stenting}

The intention was to cover completely the obturating plaque without residual stenosis. This could be done by either primary stenting or performing PTCA first. There was no need to wait for the angiographic result after initial PTCA if it was decided to proceed with stent implantation.

\section{Concomitant medication}

All patients received acetylsalicylic acid (ASA, aspirin) $100 \mathrm{mg}$ for at least 14 days before the intervention. Patients scheduled for elective surgery also received clopidogrel $75 \mathrm{mg}$ daily from four days before the intervention. Heparin (5000 IU) was given to all patients as an intravenous bolus before the procedure and then by infusion during the procedure at doses that would achieve a 2.5 -fold prolongation of activated prothrombin time. After the intervention all patients were prescribed ASA $100 \mathrm{mg} /$ day, indefinitely, and clopidogrel $75 \mathrm{mg}$ daily for four weeks.

\section{Quantitative coronary angiography}

A CAAS II research system (Pie Medical Imaging, Maastricht, the Netherlands) was used for automated contour detection and quantification. The system and validation data have been published as have been the measurement procedures. ${ }^{78}$ Angiography was performed before and after all interventions and at angiographic follow up with identical projections and analyses. Frames were selected as recommended by Herrington and Walford. ${ }^{9}$ Analysis followed the guidelines proposed by Reiber et al. ${ }^{10}$ Lesion length, mean diameter within the lesion (mean stenosis diameter), and minimum lumen diameter were calculated for the target vessel segment. Also, diameter stenosis and minimum lumen diameter were measured $5 \mathrm{~mm}$ from each stent edge. Instent restenosis was defined as percentage diameter stenosis $>50 \%$ at control angiography.

\section{Statistical analysis}

Continuous variables are expressed as the mean (SD). MannWhitney tests were used to assess differences in continuous variables between the intervention groups. $\chi^{2}$ tests assessed the dependence between categorical variables. Effects of potential risk factors for restenosis were analysed by a linear regression model for continuous variables. A stepwise logistic regression model tested all qualitative and quantitative lesion

Table 1 Patient baseline characteristics

\begin{tabular}{llll}
\hline & $\begin{array}{l}\text { Short stent } \\
\text { group } \\
(\mathbf{n}=\mathbf{4 0 0 )}\end{array}$ & $\begin{array}{l}\text { Conventional } \\
\text { stent group } \\
\text { (n=430) }\end{array}$ & p Value \\
\hline Age (years) & $64(9)$ & $64(10)$ & 0.90 \\
Men & $304(76 \%)$ & $322(75 \%)$ & 0.82 \\
CCS angina class III-IV & $156(39 \%)$ & $163(38 \%)$ & 0.88 \\
Hypertension & $316(79 \%)$ & $344(80 \%)$ & 0.68 \\
Hypercholesterolaemia & $300(75 \%)$ & $327(76 \%)$ & 0.88 \\
Diabetes mellitus & $104(26 \%)$ & $103(24 \%)$ & 0.62 \\
Multivessel coronary disease & $212(53 \%)$ & $237(55 \%)$ & 0.48 \\
\hline Data are mean (SD) or number (\%). & & \\
CCS, Canadian Cardiovascular Society. & & \\
\hline
\end{tabular}

Table 2 Lesion baseline characteristics

\begin{tabular}{llll}
\hline & $\begin{array}{l}\text { Short stent } \\
\text { group } \\
(\mathbf{n}=464)\end{array}$ & $\begin{array}{l}\text { Conventional } \\
\text { stent group } \\
(\mathbf{n = 4 3 0 )}\end{array}$ & p Value \\
\hline De novo lesion & $385(83 \%)$ & $353(82 \%)$ & 0.90 \\
Total occlusion & $9(1.9 \%)$ & $10(2.2 \%)$ & 0.78 \\
Left anterior descending artery & $158(34 \%)$ & $155(36 \%)$ & 0.66 \\
Left circumflex artery & $93(20 \%)$ & $95(22 \%)$ & 0.75 \\
Right coronary artery & $144(31 \%)$ & $124(29 \%)$ & 0.70 \\
Coronary artery branches & $60(13 \%)$ & $43(10 \%)$ & 0.45 \\
Venous coronary bypass & $9(2 \%)$ & $13(3 \%)$ & 0.68 \\
Lesion morphology & $316(68 \%)$ & $280(65 \%)$ & 0.66 \\
$\quad$ Eccentric & $60(13 \%)$ & $69(16 \%)$ & 0.28 \\
Diffuse & $186(40 \%)$ & $163(38 \%)$ & 0.64 \\
AHA type A/B1 lesions & $278(60 \%)$ & $267(62 \%)$ & 0.76 \\
AHA type B2/C lesions & & & \\
\hline Data are number (\%). & & & \\
AHA, American Heart Association. & &
\end{tabular}

characteristics independently, and then analysed all independent variables associated significantly with restenosis by a backward approach. Probability values of $p<0.05$ were considered significant.

\section{RESULTS}

Of 536 consecutive patients undergoing a percutaneous coronary intervention 400 patients with 464 stenotic coronary lesions met the criteria for short stenting and received a short stent. For the matched pairs analysis 430 control patients, with 430 lesions treated by conventional stenting, were selected from a registry. No match could be found for 34 lesions $(7.3 \%)$ in the short stent group. Baseline clinical and angiographic data were comparable between groups (tables 1 and 2).

\section{Immediate results}

The shortest available stent $(\leqslant 9 \mathrm{~mm}$ ) was implanted in 371 of 464 lesions ( $80.0 \%$ ); however, an additional stent had to be implanted subsequently in 22 of these 371 lesions $(5.9 \%)$ because of persisting residual stenoses $>45 \%$ or dissection. A longer stent was inserted in 93 of 464 lesions (20.0\%) of the short stent group. Stents used for short stenting were 397 MultiLink stents (Guidant), 79 NIR stents (Medinol Ltd), and 10 other stents. Angiographic analysis of the short stent group showed residual diameter stenosis (from 25-45\%) in 87 of $464(18.8 \%)$ lesions caused by residual plaque outside the stent. Dissections were observed in 154 lesions, of which $45(29.2 \%)$ were not fully covered by the stent.

Table 3 Procedural data and baseline characteristics of quantitative coronary angiography

\begin{tabular}{llll} 
& $\begin{array}{l}\text { Short stent } \\
\text { group } \\
(\mathbf{n = 4 6 4 )}\end{array}$ & $\begin{array}{l}\text { Conventional } \\
\text { stent group } \\
(\mathbf{n}=430)\end{array}$ & p Value \\
\hline Stent length (mm) & $9.8(4)$ & $16.3(7)$ & 0.0001 \\
$\begin{array}{l}\text { Nominal device diameter (mm) } \\
\text { Inflation pressure (atm) }\end{array}$ & $2.9(0.5)$ & $3.1(0.5)$ & 0.45 \\
Device:artery ratio & $13(3)$ & $14(4)$ & 0.72 \\
Reference diameter (mm) & $1.13(0.1)$ & $1.12(0.1)$ & 0.88 \\
Diameter stenosis, before (\%) & $2.9(0.5)$ & $3.0(0.5)$ & 0.40 \\
Minimum lumen diameter, before & $0.76(14)$ & $76.2(11)$ & 0.62 \\
(mm) & $1.6(0.5)$ & $0.74(0.3)$ & 0.18 \\
Mean stenosis diameter, before & $1.7(0.5)$ & 0.76 \\
(mm) & $10.2(6)$ & $11(6)$ & 0.82 \\
Plaque area (mm $\left.{ }^{2}\right)$ & $11.5(8)$ & $12.2(6)$ & 0.38 \\
Lesion length (mm) & & & \\
\hline Data are mean (SD). & & & \\
\hline
\end{tabular}


Table 4 Clinical and angiographic outcomes

\begin{tabular}{llll}
\hline & $\begin{array}{l}\text { Short stent } \\
\text { group } \\
(\mathbf{n = 4 6 4 )}\end{array}$ & $\begin{array}{l}\text { Conventional } \\
\text { stent group } \\
(\mathbf{n = 4 3 0 )}\end{array}$ & p Value \\
\hline Angiographic success & $458(99 \%)$ & $417(97 \%)$ & 0.26 \\
Procedural success & $458(99 \%)$ & $417(97 \%)$ & 0.26 \\
Final minimum lumen diameter & $2.6(0.5)$ & $2.7(0.4)$ & 0.18 \\
(mm) & & & \\
Final mean stenosis diameter (mm) $2.9(0.5)$ & $2.9(0.4)$ & 0.66 \\
Final diameter stenosis (\%) & $14(13)$ & $16(12)$ & 0.08 \\
Acute gain (mm) & $1.8(0.5)$ & $1.9(0.4)$ & 0.24 \\
Final plaque area (mm ${ }^{2}$ ) & $2.7(3)$ & $2.3(2.5)$ & 0.07 \\
\hline Data are mean (SD) or number (\%). & & \\
\hline
\end{tabular}

Stents used for conventional stenting were 276 MultiLink stents, 111 NIR stents, and 43 other stents. Quantitative coronary angiography showed residual diameter stenosis (from $25-45 \%$ ) outside the stent in 16 of 430 (3.7\%) lesions and dissections in 64 stented lesions, which persisted in six (9.4\%) cases after conventional stenting. The stent was significantly shorter in the short stent group; all other procedural data and lesion characteristics were comparable between groups (table 3 ).

Major adverse cardiac events ((MACE) myocardial infarction, TVR, or death) occurred in seven patients of the short stent group, comprising five cases of non-ST elevation myocardial infarction and two of ST elevation myocardial infarction caused by vessel occlusion. Similarly, in the conventional stent group, the five cases of MACE were three non-ST elevation myocardial infarctions and two ST elevation myocardial infarctions. Baseline lesion characteristics, angiographic success (diameter stenosis $<30 \%$ within the stent and diameter stenosis $<50 \%$ in target vessel), and procedural success (angiographic success and absence of MACE) were similar between the two groups (table 4). Glycoprotein IIb/IIIa antagonists were administered to 13 of 400 patients receiving short stents (3.3\%) and 19 of 430 patients receiving conventional stents $(4.4 \%)$.

\section{Clinical follow up}

Five patients in the short stent group and seven in the conventional stent group experienced recurrent angina pectoris, Canadian Cardiovascular Society class III or IV, during follow up. MACE occurred in two patients of the short stent group and three of the conventional stent group, all of whom died during the follow up period. The target vessel was revascularised in the presence of clinical symptoms or a positive stress test and a diameter stenosis $>50 \%$. This was done in significantly $(p=0.0018)$ fewer patients of the

Table 5 Angiographic outcome after six months

\begin{tabular}{llll}
\hline & $\begin{array}{l}\text { Short stent } \\
\text { group } \\
(\mathbf{n = 4 3 1 )}\end{array}$ & $\begin{array}{l}\text { Conventional } \\
\text { stent group } \\
(\mathbf{n}=381)\end{array}$ & p Value \\
\hline Diameter stenosis (\%) & $32(20)$ & $40(23)$ & 0.0016 \\
Minimum lumen diameter (mm) & $2.0(0.7)$ & $1.8(0.65)$ & 0.036 \\
Mean stenosis diameter (mm) & $2.4(0.6)$ & $2.1(0.6)$ & 0.014 \\
Late loss (mm) & $0.6(0.6)$ & $0.75(0.5)$ & 0.0001 \\
Loss index & $32(27)$ & $46(36)$ & 0.0001 \\
Net gain (mm) & $1.2(0.7)$ & $1.1(0.7)$ & 0.64 \\
Net gain index & $41(22)$ & $36(26)$ & 0.74 \\
Neo-plaque area (mm $\left.{ }^{2}\right)$ & $2.3(3.8)$ & $3.8(5)$ & $<0.001$ \\
Net plaque reduction (mm $\left.{ }^{2}\right)$ & $5.4(4.8)$ & $4.7(3)$ & 0.45 \\
Length of in-stent restenosis (mm) & $8.2(4)$ & $13.5(2)$ & 0.0001 \\
Number of lesions with restenosis & $68(15.8 \%)$ & $93(24.4 \%)$ & 0.0071 \\
(\%) & & & \\
\hline Data are mean (SD) or number (\%). & & \\
\hline
\end{tabular}

short stent group (58 of $431(13.5 \%)$ ) than in the conventional stent group (95 of $381(24.9 \%)$ ). They were treated with coronary artery bypass grafting $(\mathrm{n}=8 v \mathrm{n}=19$, respectively) and percutaneous coronary interventions ( $\mathrm{n}=50 v \mathrm{n}=76$, respectively).

\section{Angiographic follow up}

In 361 of 391 patients in the short stent group (92.3\%), angiography was repeated at 185 (13) days on 431 of 454 of lesions $(94.9 \%)$. Similarly, in 381 of 414 patients in the conventional stent group $(92.0 \%)$, angiography was performed at 182 (15) days on 381 of 414 of lesions (92.0\%) (table 5). In-segment restenosis was significantly $(p=0.0071)$ less common in short stented lesions (68 of $431(15.8 \%)$ ) than in conventionally stented lesions (93 of $381(24.4 \%))$, as was late lumen loss (table 5 ). Both groups had the same number of restenoses in the vessel segment adjacent to the stent (9 of $68 v 11$ of 93, $\mathrm{p}=0.98$ ). Proliferative or diffuse in-stent restenoses developed in five lesions of the conventional stent group and in none of the short stent group $(p=0.14)$. In-stent restenosis was longer in the conventional stent group (table 5). The restenosis rate in lesions treated by short stenting did not differ whether the shortest available (53 of $349(15.2 \%)$ ) or a longer stent was used ( 15 of $82(18.3 \%), p=0.082)$.

In the univariate analysis, diffuse lesion type, reference diameter, final minimum lumen diameter, and final mean diameter were all significantly correlated with restenosis in the short stent group. However, in the multivariate analysis, only reference diameter independently predicted restenosis (table 6). When all treated lesions were included in the multivariate model, stent length, reference diameter, and diffuse lesion type predicted restenosis independently. The use of a single stent $\leqslant 9 \mathrm{~mm}$ long independently predicted the absence of restenosis.

\section{DISCUSSION}

In-stent restenosis is the major limitation to using bare metal stents. Moreover, a diffuse in-stent restenosis $>10 \mathrm{~mm}$ has a high probability of recurrence. ${ }^{11}$ Stent length, among other parameters, was found to be predictive for in-stent restenosis in several investigations. ${ }^{4}{ }^{12}$ A recent meta-analysis of several stent trials showed that the stented segment length predicts in-stent restenosis independently of the lesion length. ${ }^{5}$ Although more than $50 \%$ of all lesions treated by percutaneous coronary intervention in most large interventional studies are $<10 \mathrm{~mm}$ long, only $22 \%$ of MultiLink stents distributed in Europe are $<12 \mathrm{~mm}$ (Guidant Co, sales report Europe 2003). Colombo et $a l^{13}$ reported that multiple short stents inserted into long stenoses at spots with significant residual stenosis after PTCA produced a lower restenosis rate than did a single long stent. Complete stent coverage of an extensive but non-obstructive plaque is unnecessary in preventing restenosis.

\section{Methodological aspects}

The criterion that was used to measure lesion length by quantitative angiography (length of plaque causing $>50 \%$ diameter reduction) reflects more precisely the extent of clinically relevant stenoses and allows standardisation of measurements, in contrast to overall lesion length. Also, the algorithm used measures a shorter lesion length than does measuring the overall lesion length.

Most of our interventions consisted of an initial PTCA with balloons, which usually shortened the significantly stenosed vessel segment. Since we did not observe an increased incidence of restenosis in the vessel segments adjacent to the stent, although they are affected by balloon angioplasty, we can assume that stent length, rather than the endothelial 
Table 6 Analysis of restenosis after short stent implantation

\begin{tabular}{|c|c|c|c|c|}
\hline & \multicolumn{3}{|c|}{ Univariate analysis } & \multirow{2}{*}{$\begin{array}{l}\text { Multivariate analysis: restenosis } \\
\text { p Value }\end{array}$} \\
\hline & Restenosis & No restenosis & p Value & \\
\hline Diffuse lesion & $20 / 68(29.4 \%)$ & $48 / 363(13.2 \%)$ & 0.0003 & 0.08 \\
\hline Reference diameter $(\mathrm{mm})$ & $2.8(0.5)$ & $3.1(0.4)$ & 0.0023 & 0.003 \\
\hline Acute gain $(\mathrm{mm})$ & $1.7(0.5)$ & $1.9(0.5)$ & 0.037 & 0.12 \\
\hline Final minimum lumen diameter $(\mathrm{mm})$ & $2.4(0.5)$ & $2.6(0.4)$ & 0.03 & 0.10 \\
\hline Final mean stenosis diameter $(\mathrm{mm})$ & $2.7(0.5)$ & $2.9(0.4)$ & 0.035 & 0.22 \\
\hline
\end{tabular}

damage caused by the intervention, is the determining factor for restenosis. The mean postprocedural diameter stenosis adjacent to the stent was $<20 \%$ (data not shown) and consistent with a high likelihood for a favourable long term result after balloon angioplasty. ${ }^{14}$ Furthermore, although residual plaque causing a $25-45 \%$ diameter stenosis was left unstented in $19 \%$ of all short stented lesions, we observed no increased incidence of restenosis here.

\section{Clinical and angiographic results}

We previously showed in 331 consecutive patients that using only the shortest available stent ( 8 or $9 \mathrm{~mm}$ ) in 221 of 424 lesions $(52.1 \%)$ was sufficient for angiographic success. ${ }^{6}$ The restenosis rate was remarkably low in lesions that received a $\leqslant 9 \mathrm{~mm}$ stent and in lesions that received a longer but the shortest possible stent. Results of the investigation presented here were in accordance with our feasibility study of short stenting published previously. ${ }^{6}$ We showed in both investigations that most coronary lesions can be treated successfully with the shortest stent available when preceded by PTCA as the primary treatment. A second stent was needed in very few cases $(5.9 \%)$; however, in all other stent implantations the use of an additional stent was not necessary $(p=0.0001)$. We are not aware of other clinical trials of short stenting or of short stents used in a similar proportion of total stent implantations. Only a few trials with bare metal stents have reported comparable rates of restenosis or TVR; however, these lesions were preselected or angiographic control was infrequent, which may also account for the low number of revascularisation procedures. ${ }^{15-18}$

\section{Clinical implications}

DES reduce the rate of restenosis to about $2 \%$ in non-complex lesions and to about $8 \%$ in long complex lesions. ${ }^{1}$ Treatment costs for DES are significantly higher than those for bare metal stents at present, but this difference diminishes within one year when costs for repeat revascularisation procedures are included. ${ }^{19}$ Geenberg et $a{ }^{2}$ recently calculated that treatment with the available DES would be cost saving for patients with a TVR rate $>20 \%$ and cost effective for patients with a TVR rate $>12 \%$ after bare metal stents. With the TVR rate of $14.2 \%$ after short stenting, routine use of DES would not have saved costs compared with the use of conventional stents to treat lesions. Furthermore, our results indicate that short stenting is cost effective as compared with DES when lesions in vessels $>2.7 \mathrm{~mm}$ are treated with bare metal stents (TVR $11.0 \%$, data not shown), which accounted for $91.3 \%$ of all lesions stented.

\section{Limitations}

Short stenting was evaluated prospectively, whereas the control group was analysed retrospectively. Although both patients and lesions were well matched between the two groups, the absence of randomisation may have introduced a selection bias that affected the results.
Patients with lesions that had a $>3 \mathrm{~cm}$ long $>50 \%$ diameter stenosis were excluded because the long term results are considerably less favourable with bare metal stents than with surgical revascularisation or DES in these cases. $^{20}$ Lastly, stent design also influences the rate of restenosis. ${ }^{21}$ Patients of the control group and of the short stent group were treated mainly with MultiLink stents. Since then the design of the MultiLink stents, implanted in most of our patients, has been improved, which has been shown to improve long term angiographic parameters, and this may have affected the results. ${ }^{22}$ However, none of the stent types used in this study exhibited an increased restenosis rate in larger investigations (for example, as gold stents). Furthermore, analysis of the stent type used did not show an impact on restenosis within or between the two groups.

\section{Conclusions}

Our goal was to use the shortest possible stent for a successful outcome in a series of consecutive patients with non-selected coronary artery stenoses. We showed that the shortest available stent $(\leqslant 9 \mathrm{~mm})$ was sufficient in the majority of cases. Compared with a control group with conventional stent lengths covering all plaque segments, all our patients achieved similar immediate results, both clinical and angiographic, with significantly shorter stent lengths. Therefore, restenosis and the consequent need for target lesion revascularisation can be reduced by implanting short stents, without increasing the risk of restenosis in immediately adjacent vessel segments. The low restenosis rate with short stenting suggests an economically attractive alternative to the routine use of DES in suitable patients.

\section{Authors' affiliations}

U Dietz, N Holz, C Daver, H Lambertz, Deutsche Klinik für Diagnostik, Wiesbaden, Germany

\section{REFERENCES}

1 Hill RA, Dundar $Y$, Bakhai A, et al. Drug-eluting stents: an early systematic review to inform policy. Eur Heart J 2004;25:902-19.

2 Greenberg D, Bakhai A, Cohen DJ. Can we afford to eliminate restenosis? Can we afford not to? J Am Coll Cardiol 2004;43:513-8.

3 Kobayashi Y, De Gregorio J, Kobayashi N, et al. Stented segment length as an independent predictor of restenosis. J Am Coll Cardiol 1999;34:651-9.

4 Kereiakes D, Linnemeier TJ, Baim DS, et al. Usefulness of stent length in predicting in-stent restenosis (the MULTI-LINK stent trials). Am J Cardiol 2000;86:336-41.

5 Mauri L, O'Malley AJ, Cutlip DE, et al. Effects of stent length and lesion length on coronary restenosis. Am J Cardiol. 2004;93: 1340-6, A5).

6 Dietz U, Holz N, Dauer C, et al. Short stent implantation for routine use is feasible in a high proportion of coronary interventions and yields a low restenosis rate. Cardiology 2005; 103:212-8.

7 Hausleiter J, Jost S, Nolte CW, et al. Comparative in-vitro validation of eight first- and second-generation quantitative coronary angiography systems. Coron Artery Dis 1997;8:83-90.

8 Dietz U, Rupprecht HJ, Brennecke R, et al. Comparison of QCA systems. Int J Card lmaging 1997;13:271-80.

9 Herrington D, Walford G. Optimal frame selection for QCA. In: Reiber JHC, Serruys PW, eds. Advances in quantitative coronary arteriography. Dordrecht: Kluwer Academic Publishers, 1993:125-35. 
10 Reiber JH, van Eldik Helleman P, Visser Akkerman N, et al. Variabilities in measurement of coronary arterial dimensions resulting from variations in cineframe selection. Cathet Cardiovasc Diagn 1988;14:221-8

11 Storger H. Diffuse in-stent restenosis. J Interv Cardiol 2001;14:587-96.

12 Goldberg SL, Loussararian A, De Gregorio J, et al. Predictors of diffuse and aggressive intra-stent restenosis. J Am Coll Cardiol 2001;37:1019-25.

13 Colombo A, De Gregorio J, Moussa I, et al. Intravascular ultrasound-guided percutaneous transluminal coronary angioplasty with provisional spot stenting for treatment of long coronary lesions. J Am Coll Cardiol 2001;38:1427-33.

14 Holmes DR Jr, Kip KE, Yeh W, et al. Long-term analysis of conventional coronary balloon angioplasty and an initial "stent-like" result. The NHLBI PTCA Registry. J Am Coll Cardiol 1998;32:590-5.

15 Agema WR, Monraats PS, Zwinderman AH, et al. Current PTCA practice and clinical outcomes in the Netherlands: the real world in the pre-drug-eluting stent era. Eur Heart J 2004:25:1163-70.

16 Unverdorben M, Sippel B, Degenhardt R, et al. Comparison of a silicon carbide-coated stent versus a noncoated stent in human beings: the Tenax versus Nir stent study's long-term outcome. Am Heart J 2003;145:e17.

17 Serruys PW, Jsselmuiden S, Hout B, et al. Direct stenting with the Bx VELOCITY balloon-expandable stent mounted on the Raptor rapid exchange delivery system versus predilatation in a European randomized trial: the VELVET trial. Int J Cardiovasc Intervent 2003;5:17-26.

18 Jorgensen E, Kelbaek H, Helqvist S, et al. Low restenosis rate of the NIR coronary stent: results of the Danish multicenter stent study (DANSTENT)-a randomized trial comparing a first-generation stent with a second-generation stent. Am Heart J 2003;145:e5.

19 Lemos PA, Serruys PW, van Domburg RT, et al. Unrestricted utilization of sirolimus-eluting stents compared with conventional bare stent implantation in the "real world": the rapamycin-eluting stent evaluated at Rotterdam Cardiology Hospital (RESEARCH) registry. Circulation 2004; 109:190-5

20 Kornowski R, Mehran R, Hong MK, et al. Procedural results and late clinical outcomes after placement of three or more stents in single coronary lesions. Circulation 1998;97:1355-61.

21 Pache J, Kastrati A, Mehilli J, et al. Intracoronary stenting and angiographic results: strut thickness effect on restenosis outcome (ISAR-STEREO-2) trial. J Am Coll Cardiol 2003;41:1283-8.

22 Rittersma SZ, de Winter RJ, Koch KT, et al. Impact of strut thickness on late luminal loss after coronary artery stent placement. Am J Cardiol 2004;93:477-80.

\section{IMAGES IN CARDIOLOGY}

\section{Percutaneous removal of embolised vegetation from left main coronary artery}

A

55 year old man presented with acute central chest pain two weeks after undergoing redo aortic valve replacement for Streptococcus mitis prosthetic endocarditis. His past history included cadaveric renal transplantation for adult polycystic kidney disease. He was receiving intravenous antibiotics at presentation and was afebrile with a normal white count. His ECG is shown in the upper panel.

Primary percutaneous coronary intervention (PCI) was planned. Diagnostic angiography via the right radial demonstrated a filling defect in the left main stem not present at preoperative angiography (panel A).

Emergency bypass surgery was considered to be of prohibitively high risk. In view of the likely haemodynamic instability a percutaneous left ventricular assist device (PVAD) (TandemHeart) was inserted (panel B, arrow). The 21 French venous cannula which was passed across the atrial septum (after predilatation of a patent foramen ovale) and the 17 French femoral artery cannula allowed a flow of approximately $3 \mathrm{l} / \mathrm{min}$. Following this the vegetation was aspirated using an Angiojet device. The filling defect was successfully removed but the left main ostium appeared compromised (panel C). A $3.5 \times 20 \mathrm{~mm}$ Taxus stent was deployed in the left main ostium, which was then post-dilated with a $4 \times 20$ Quantum non-compliant balloon. An excellent angiographic result (panel D) was obtained with no evidence of major distal embolism. The PVAD was removed after 48 hours. Over the next week, the patient's ejection fraction improved from $25 \%$ to $45 \%$ and he was discharged home on day 10 after intervention.
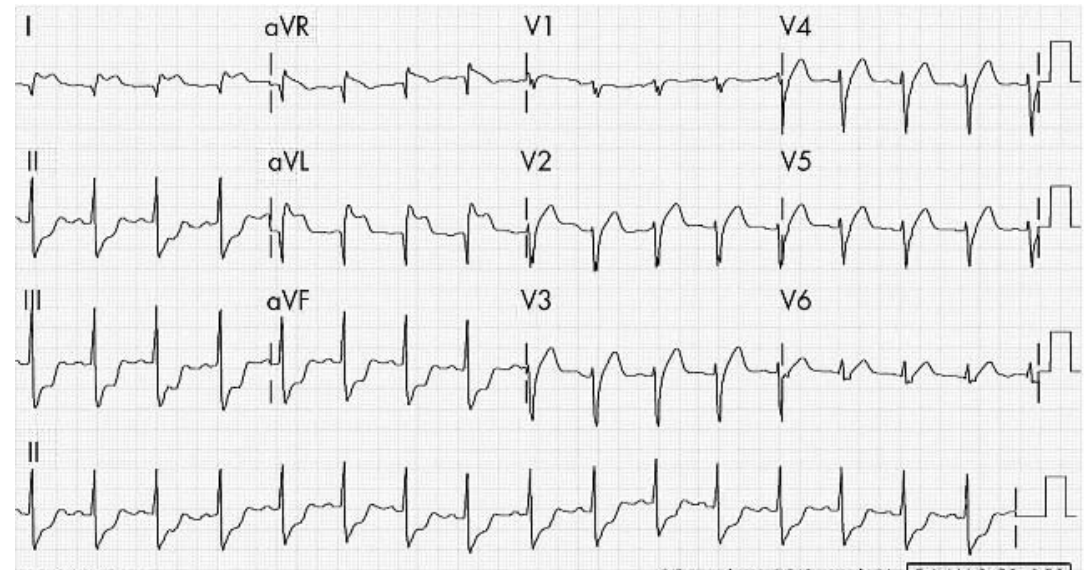

Loc 30021
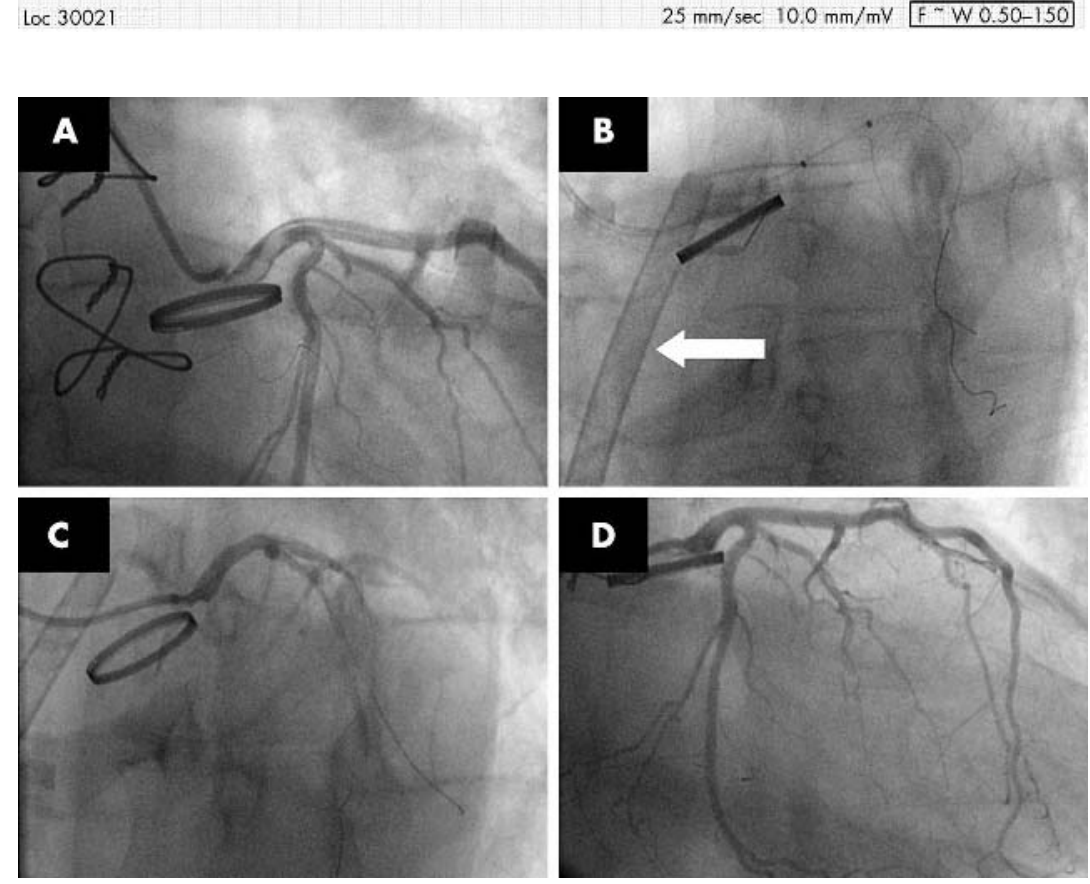

W H T Smith

$M$ R Wolff

T Kohmoto

whs@medicine.wisc.edu 